\title{
简析建筑工程施工中的绿色节能施工技术应用
}

\author{
王峰 \\ 内蒙古金安建筑安装工程有限责任公司 \\ DOI:10.18686/bd.v2i2.1228
}

[摘要] 建筑工程施工中的绿色节能施工技术应用是控制建筑工程施工成本、保障建设企业经济利益的需要, 也能有效维 护施工环境,节省社会资源, 其对于建筑业以及人类社会发展都具有重要意义。基于此, 本文阐述了建筑绿色节能施工的主要 特征及其意义, 论述分析了影响建筑工程绿色节能施工的主要因素, 对建筑工程施工中的绿色节能施工技术应用进行了简 要分析。

[关键词] 建筑绿色节能施工; 特征; 意义; 建筑工程施工; 影响因素; 应用

建筑工程施工中的绿色节能施工要求尊重自然、保护 生态、与自然协调共生,尽可能减少人工环境对自然的破坏, 最大限度地提高建筑资源和能源的利用率; 并且绿色节能 施工有利于人们的身心健康, 避免或最大限度地减少环境 污染,其要求采用耐久、可重复的环保型绿色建材,充分利用 太阳能、风能等自然清洁能源, 加强绿化, 改善环境; 而且建 筑工程施工中绿色节能施工要求建筑空间和使用功能适应 社会发展变化。为了充分发挥建筑工程施工中的绿色节能 施工的作用, 以下就建筑工程施工中的绿色节能施工技术 应用进行了探讨分析。

\section{1 建筑绿色节能施工的主要特征及其意义}

建筑绿色节能施工主要是对建筑资源进行有效利用, 具体表现为:一是减少建筑材料、各种资源和不可再生能源 的使用; 二是利用可再生能源和材料; 三是设置废物回收系 统,利用回收材料;四是在结构允许的条件下重新使用旧材 料; 五是减少污染物的排放, 最大限度地减少对周围环境的 影响。同时,绿色施工也是融合保护环境亲和自然、舒适、健 康、安全于一体的建筑。

建筑绿色节能施工对建筑工程建设具有重要意义, 并 且建筑工程施工中对可生能源的利用以及提高能源利用效 率, 可以缓解目前资源紧张和环境污染的局面。建筑工程节 能包括照射、采暖和利用空调等方面,在建筑设计、建造和 使用过程中采用新型的节能环保材料、施工设备和技术、产 品等,执行节能标准,加强对可生能源的再利用, 减少供热供 应、照明、热水等能耗,加强对自然光利用的同时提高空调 的制冷、制热系统的效率等措施。建筑工程施工中的绿色节 能不仅有利于建筑的便利性和舒适性, 同时还能提高能源 的利用效率。

\section{2 影响建筑工程绿色节能施工的主要因素}

影响建筑工程绿色节能施工的因素主要有:(1) 建筑废 气的环境污染。建筑业的废气主要来源于建筑装修材料,如 油漆、涂料等。建筑业废气的排放量较小,对环境空气的影 响不大。但是由于此类废气具有污染物种类较多、毒性较大 的特点以及产生的地点一般都是人类活动较为频繁的地
方, 通风状况一般都不佳, 故对人的危害较大。有关部门已进 行了一些模拟试验的研究表明, 在发生火灾时, 室内装修材 料中的有机高分子材料和木材, 产生的烟雾和毒气的对人 的危害性更大, 常见的有毒有害气体包括一氧化碳, 二氧化 碳、硫化氢、氭化氢、光气等。(2)施工噪声的环境污染。施工 噪声是指建筑工地现场产生的环境噪声, 主要是由施工机 械工作产生的。不同类型的施工机械产生的噪声强度也有 区别。据测建筑场地清理工程噪声约为 $80 \mathrm{~dB} \sim 85 \mathrm{~dB}(\mathrm{~A})$, 地 基工程为 $75 \mathrm{~dB} \sim 85 \mathrm{~dB}(\mathrm{~A})$, 安装工程为 $75 \mathrm{~dB} \sim 85 \mathrm{~dB}(\mathrm{~A})$, 整修 工程为 $85 \mathrm{~dB} \sim 95 \mathrm{~dB}(\mathrm{~A})$ 。因此,施工场地的噪声一般均超过 国家施工场界噪声限值的标准, 由于近年来城市化进程的 不断加快,很多工程作业几乎是在居民窗下进行, 严重干扰 了居民的正常生活和身体健康。恶劣的噪声常常使周围居 民难以忍受而采取措施阻止施工, 使一些建设项目被迫停 工,甚至有时会发生流血冲突和法律诉讼。关于施工现场噪 声扰民的诉讼近年来呈逐年上升的趋势。(3)粉尘的环境污 染。建筑粉尘是地表扬尘的主要来源, 是影响城市环境空气 质量的重要因素, 且近年来其对环境空气的 TSP 贡献率有 逐年上升的趋势。建筑粉尘污染主要是指水泥、石灰、沙石 和回填土等建筑原材料在运输、堆放和使用过程中由于人 为原因或某些气象因素造成的部分建筑原材料小颗粒散失 到环境空气中所造成, 也包括由于建筑工程施工造成的裸 露地表对环境空气质量的影响。(4)建筑垃圾的环境污染。建 筑垃圾大多为固体废弃物, 一般是在建设过程中或旧建筑 物维修、拆除过程中产生的。目前, 我国建筑垃圾的数量已 占到城市垃圾总量的 30\% 40\%。绝大部分建筑垃圾未经 任何处理,便被施工单位运往郊外或乡村, 采用露天堆放或 填埋的方式进行处理,耗用大量的征用土地费、垃圾清运等 建设经费,同时,清运和堆放过程中的遗撒和粉尘、灰砂飞扬 等问题又造成了严重的环境污染。

\section{3 建筑工程施工中的绿色节能施工技术应用分析}

3.1 建筑工程施工中的清洁与环保绿色节能施工技术 应用分析。具体体现在:(1)空气污染控制。建筑工程施工过 程中必然会出现扬尘、飞尘等,其中固体悬浮颗粒充斥大气 
中,会引发严重的空气污染,对此应该进行绿色处理,施工所 在的出口需要增设洗车槽, 从而减少对周围道路的污染与 侵蚀,遇到关键施工环节,例如: 土方挖掘施工等,应该采取 设置围栏、增设酒水车或高压喷雾等方法来控制扬尘污染。 (2)噪音控制。噪音污染作为一种非视觉化的污染形式,扰乱 人们的生活, 高强噪音所引发的振动甚至会对周围建筑结 构带来破坏作用。必须加大噪音管理, 积极控制噪音, 这也是 绿色节能施工技术应用的根本任务之一。首先, 噪音施工要 避开周围居民休息时间段; 其次,尽量优选噪音小、振动小 的施工机械设备,同时选择隔声、隔震等技术措施, 在施工场 地设置封闭式机棚, 作为专门噪声工具施工空间, 达到与外 界隔绝的效果。最后, 专门围绕噪音大小进行监测, 确保其处 于国家规定的安全标准。(3)水污染控制。建筑工程施工水体 污染源具体涵盖施工建设过程产生的废水与生活污水,对 此需要施工区域内应设置污染处理专区, 例如: 预先设置化 粪池、沉淀池等, 确保污水、废水等经过处理后尽量能够被 循环利用, 从而节约水资源, 同时, 选择隔水效果强的边坡支 护技术,防止地下水体受到污染。

3.2 建筑工程施工中的资源节约与回收利用绿色节能 施工技术应用分析。主要表现为:(1)合理使用原材料。原材 料对于建筑工程施工非常重要, 其支出是建筑工程施工成 本预算的重要组成部分。对此需要预先制定出较为精细、合 理的原材料预算方案,并加大采购管理与监督,实行计划采 购战略,按照不同施工阶段的材料、物资需求量与需求类型 进行分批次的计划采购，从而防止材料剩余造成的资源浪 费, 同时要保障建筑工程施工的顺利实施, 保证施工进度和 周期,从而确保材料在有效期内被充分使用。(2)水资源的高 效利用。注重施工现场节水管理,并实行雨水、污水、废水分 流排放制度, 采用计量管理制度来强化水资源使用情况的 监督。施工材料搅拌、调配过程中,要本着节水的原则使用 水资源, 减少水资源的无故浪费现象。在施工现场创建水资 源回收、再利用系统,充分利用雨水资源,并对可回收再利用 的废水资源进行充分的再利用。(3)电能资源的有效利用。实 行用电指标管理制度,从现场施工、办公、设备用电、施工人 员用电都严格依照相关指标进行监测管理。提倡选择节能
环保型照明设备、施工机械等,尽量延长白天作业时间,充分 利用自然光源, 通过科学地安排施工程序, 确保高效施工, 缩 短施工进程,从而达到节能环保的目标。(4)建筑垃圾的处理 与回收。建筑工程施工中所产生的建筑垃圾与生活垃圾要 分开存放,其中建筑垃圾要实施分类处理,从中挑选一部分 进行回收再利用, 不可回收的部分则应统一运输处理。生活 垃圾则应该装袋运输。有必要设置封闭式垃圾池, 实施封闭 式处理。(5)节省施工用地与空间。要想达到绿色节能施工的 效果, 就必须尽量减少对空间和施工用地的使用,必须对工 程所在地附近的设施、管线、设备等的分布情况作出细致的 了解,在此基础上来规划施工空间、规划施工占地,维护施工 地域附近设施与资源的安全。在保证健康施工、安全施工、 环保施工的基础上来规划施工面积, 要确保施工平面场地 紧凑布局, 控制废弃物的出现, 运输通道布置要灵活得当, 不 能过多地占地、占用空间, 可以尝试设置环形通道, 以此控制 施工占地空间。

\section{4 结束语}

综上所述, 建筑工程施工需要耗费大量的资源, 并且建 筑工程施工中产生的噪音、灰尘等方面的污染,给人们的正 常生活带来严重影响。而绿色节能施工技术在建筑工程施 工中应用可以达到节能减排、节省资源、保护环境的目标, 对于建筑业的可持续发展具有重要意义, 因此必须加强对 其进行分析。

\section{参考文献:}

[1] 李世国。探讨绿色施工技术在建筑工程中的应用 [J].门窗,2017,(03):38.

[2] 董军科。探讨节能施工技术在建筑工程中的运用 [J].中华民居(下旬刊),2014,(04):10.

[3]简玉梅.新型绿色节能技术在建筑工程施工中的应 用[J].科技创新与应用,2018,(07):158-159.

[4]梁惠惠. 绿色节能施工技术在房屋建筑工程中的应 用[J].建材与装饰,2016,(50):51-52.

[5]张博.新型绿色节能技术在建筑工程施工中的应用 [J].中国战略新兴产业,2018,(04):19. 